\title{
Analysis and Optimization of Ultra-Low-Power Rectifier with High Efficiency for Applications in Wireless Power Transmission and Energy Harvesting
}

\author{
Raphaella Luiza Resende da Silva ${ }^{1}$ (1), Sandro Trindade Mordente Gonçalves ${ }^{2}$ (1) , Christian Vollaire $^{3}$ (1), \\ Arnaud Bréard ${ }^{4}$ (D), Gláucio Lopes Ramos 5 (D) and Cássio Gonçalves do Rego ${ }^{6}$ (i) \\ ${ }^{1,2}$ Federal Center of Technological Education of Minas Gerais, Av. Amazonas, 7675, Belo Horizonte, Brazil \\ 3,4 Laboratoire Ampère, CNRS UMR 5005, Université de Lyon, 69130, Ecully, France. \\ ${ }^{5}$ Federal University of São João del-Rei, MG 443, km7, Ouro Branco, Brazil. \\ ${ }^{6}$ Federal University o Minas Gerais, Av. Presidente Antônio Carlos, 6627, Belo Horizonte, Brazil. \\ ${ }^{1}$ raphaella.lrs@gmail.com, ${ }^{2}$ sandro@cefetmg.br, ${ }^{3}$ christian.vollaire@ec-lyon, ${ }^{4}$ arnaud.breard@ec-lyon.fr, \\ ${ }^{5}$ glopesr@gmail.comand ${ }^{6}$ cassio@cpdee.ufmg.br
}

\begin{abstract}
The system capable of harvesting RF energy from the environment through an antenna and converting it into direct current energy to deliver to a load is known as rectenna. The rectifier circuit is an important part of the rectenna and its modeling is arduous since it employs a non-linear device working at extremely low power levels. In addition, there are some losses in the system. Thus, the design of a high-efficient rectifier is a great challenge. In this work, several rectifier topologies are optimized, using the Genetic Algorithm, in order to achieve the highest efficiency and output voltage. An analysis of the influence of the variables on the output of these rectifiers was also performed. The topologies under investigation were optimized for $\mathbf{- 1 5} \mathrm{dBm}$ input power and $2.45 \mathrm{GHz}$ operating frequency, in accordance with the most suitable band for energy harvesting. Under these conditions, the Monodiode Series topology presents the best performance. When the input power is $-15 \mathrm{dBm}$, it presents an output voltage of $402 \mathrm{mV}$ and an efficiency of $51.3 \%$. At that power level, the achieved efficiency is higher than that found in the literature.
\end{abstract}

Index Terms - Low Power Rectifier, Optimization, Power Harvest, Rectenna.

\section{INTRODUCTION}

In recent years there has been great progress in technology due to the advancement of microelectronics leading to the integration of systems into a single device. Moreover, portable electronic devices are increasingly versatile and powerful. However, with regard to the energy supply of these, the technology should further evolve since there is still great limitation in storage and time of charge of the batteries in spite of all research done to decrease their size and increase their efficiency. Additionally, the connection of devices to the electricity distribution network is an inconvenience to mobility and remote installation. In this way, a system that harvesting and transfers energy without wires would allow the devices to be more compact, giving them a greater freedom of movement. 
There are several methods that can be used for wireless energy harvesting and energy transfer, such as Close-Range Magnetic Induction (CRMI), electromagnetic fields guiding and focusing using Metamaterials and Electromagnetic Radiation. The CRMI was chosen in 2009 by the Wireless Power Consortium as the first standard for this purpose. This technology consists of two inductive coils, a transmitter and a receiver, and is widely applied in our everyday life, being present in toothbrush, game console and cochlear implant chargers. Although this technology is easy to implement, its application is limited by the distance between the transmitter and the receiver, which is less than 25 $\mathrm{mm}$ [1]. Recently the metamaterials have been became more important and is today one of the most investigated methods for power transmission for low distances. This type of material is an artificial compound or periodic geometries whose electromagnetic properties can be designed to exhibit characteristics not observed in natural media [2]. Metamaterials have the ability, for example, to improve antenna performance by increasing their bandwidth and gain and decreasing the value of return loss, making them more useful for efficient application in power harvesting and wireless communication systems [3].The last method, Electromagnetic Radiation, has as its main application the recharging of lithium-ion batteries. In this method, there is the transmitting source and a receiver called rectenna which is an integrated circuit with a receiving antenna used to convert the transmitter's radio frequency energy into continuous energy. However, battery recharging using electromagnetic radiation is restricted to ultra-low-power applications due to the low efficiency of the systems and the low power density available at the receiver that harvesting the available electromagnetic radiation from the air. Nevertheless, there are several advantages of using a wireless energy transmission system through electromagnetic radiation, especially when considering the battery life. If the device is in a location with difficult physical access, the repeated replacement of these batteries can be impractical as it can lead to significant human risks or to be too expensive [1].

The efficiency of the wireless power transmission and energy harvesting began to increase from the 1960 s to the 1970 s on the frequency of $2.45 \mathrm{GHz}$. Since then, new technologies have emerged in this field as the inductive coupling for short-range transmission and the resonant coupling for midrange transmission. These approaches have been used in RFID (Radio Frequency Identification), that in 1990 already operated in ISM bands such as $915 \mathrm{MHz}$ and $2.45 \mathrm{GHz}$. The $2.45 \mathrm{GHz}$ frequency has emerged as a frequency of transmission due to its advanced and efficient technological base, its location at the center of a newly licensed band called Industrial, Scientific and Medical (ISM) and its minimal attenuation through the atmosphere, even in heavy rainstorms. In the first decade of the 2000s, several wireless power applications attracted strong commercial interest, resulting in the formation of the Wireless Power Consortium (WPC).

If long-range power transmission is required, the inductive and resonant coupling is not suitable. Therefore, a wave propagation transmission and reception is required. At the receptor side, a rectenna can be used to receive and rectify the energy that reaches the receptor. Nowadays, rectennas have gained greater visibility because wireless power transmission can be performed at greater distances Brazilian Microwave and Optoelectronics Society-SBMO received 23 Aug 2019; for review 29 Aug 2019; accepted 25 Jan 2020 $\begin{array}{lllll}\text { Brazilian Society of Electromagnetism-SBMag } & \odot 2020 \text { SBMO/SBMag } & \text { ISc) BY } & \text { ISSN 2179-1074 }\end{array}$ 
than previous technologies because, despite the low power, wave propagation rather than inductive or resonant couplings, allows the receiver to stay significantly away from the receiver.

The wireless energy harvesting system consists of four blocks: antenna, the network filter, the rectifier circuit, and the low-pass filter at the output. The radiofrequency (RF) energy is harvested from the air through the rectenna which is composed of the antenna, filters and rectifier circuit set. The network filter has the purpose of matching the antenna impedance with the rectification circuit, in addition to preventing the harmonics generated by it from being re-radiated to the environment. The rectifier circuit can be constructed employing a variety of topologies that involve different numbers of diodes and capacitors. Finally, the low-pass filter at the output removes the fundamental frequency and harmonics, preserving only the DC value of the voltage [4].

In some applications the challenge of implementing the wireless energy harvesting system can bring immediate benefits due to the impracticability of energy sources such as light, wind, vibration among others causing radiofrequency to become a natural candidate for energy source to be harvesting. However, the system cannot accumulate large amounts of energy due to the low power available and large losses in the harvesting system. In addition, radio waves are sometimes reflected, diffracted and scattered, and it is very difficult to estimate the amount of radiofrequency power that can be captured [5].

A critical point of a radiofrequency energy harvesting system is the efficiency when the incident energy levels are very low, being object of study of several works presented in the literature. The rectifier circuit is an important part of the wireless energy harvesting system and several rectification topologies have been proposed to increase the efficiency of conversion from radiofrequency energy to DC. Table I shows the state of the art for rectifier circuits operating at low power.

TABLE I. STATE OF THE ART OF RECTIFIER CiRCUITS

\begin{tabular}{ccccccc}
\hline Frequency & $\begin{array}{c}\text { Input } \\
\text { Power }\end{array}$ & $\begin{array}{c}\text { Output } \\
\text { Voltage }\end{array}$ & Efficiency & $\begin{array}{c}\text { Diode } \\
\text { HSMS }\end{array}$ & Topology & References \\
\hline $950 \mathrm{MHz}$ & $-20 \mathrm{dBm}$ & $61 \mathrm{mV}$ & $0.37 \%$ & 2850 & Voltage Doubler & {$[5]$} \\
$940 \mathrm{MHz}$ & $-20 \mathrm{dBm}$ & $110 \mathrm{mV}$ & $40.1 \%$ & 7630 & Series & {$[6]$} \\
$2.45 \mathrm{GHz}$ & $-20 \mathrm{dBm}$ & $140 \mathrm{mV}$ & $15 \%$ & 2852 & Greinacher & {$[7]$} \\
$2.45 \mathrm{GHz}$ & $-20 \mathrm{dBm}$ & $200 \mathrm{mV}$ & $40 \%$ & 2852 & Greinacher & {$[8]$} \\
$900 \mathrm{MHz}$ & $-15 \mathrm{dBm}$ & $250.4 \mathrm{mV}$ & $40 \%$ & 2850 & Series & {$[9]$} \\
\hline
\end{tabular}

It can be noted in Table I that in [5] and [6], although the operating frequency is low, the highest efficiency found was $40.1 \%$. In [7] and [8] showing rectifiers operating at high frequency, the highest efficiency found was 40\%. Although [6] shows the rectifier circuit topology Series and [8] the Greinacher topology, there was no loss in efficiency when there is an increase in frequency. The value of the output voltage is even higher in [8] operating at $2.45 \mathrm{GHz}$ frequency. This shows that these circuits can operate perfectly at high frequencies. In [9], the Series topology circuit was simulated to $900 \mathrm{MHz}$ frequency and has $40 \%$ efficiency and $250.4 \mathrm{mV}$ output voltage. What differs this work 
from the others is the input power: $-15 \mathrm{dBm}$, which, in the context of energy harvesting, is still considered ultra-low-power, despite being slightly higher than the other cases presented. It is important to emphasize that all the quantities presented in Table I are the result of a simulation process.

Besides the non-linear behavior of the rectifier and the problems mentioned about the substrate used in this work, another issue arises in the rectifier design. At high frequencies, the dimensions of the microstrip tracks that connect components have an important role since the impedance of the tracks will influence the signals that travel through it. Thus, to correctly simulate a nonlinear circuit, such as the rectifier, it is necessary to model these tracks and optimize their dimensions so that the circuit meets the necessary requirements. The dimensions of the tracks and passive devices affect the impedance and the rectified output voltage of the circuit. There is an interdependence of these variables so the change of only one of them interferes in the performance of the others. In this way, the optimization process of this circuit becomes essential, having as optimization goals the passive components and the dimensions of the microstrip tracks

This paper is organized as follows: low power rectifier circuits are reported in Section II, as well as a discussion of the diodes used, loss mechanisms, and optimization algorithm. Section III presents the simulation and optimization processes of the rectifier circuits also showing the results found. In Section IV, an analysis of how the variables - input power, load, frequency, passive element, diode and input and output filter dimensions - influence the output of the different rectifier circuit topologies is performed. Finally, the determination of the most appropriate topology, the modeling, construction and measurement tests are reported in Section V.

\section{LOW POWER RECTIFIER CIRCUITS}

An energy harvesting system aims to capture the available RF energy in the air and transform it into DC power. In this way, the rectifier circuit is a fundamental part of this system and it is important to have a good project in order to guarantee its good performance. Although there are several methods of doing RF-DC conversion, diode-based rectifier circuits are more widely used, especially in the frequency range desired between $2 \mathrm{GHz}$ and $3 \mathrm{GHz}$.

In Fig. 1 the topologies of rectifier circuits most found in the literature, such as Series, Shunt, Voltage Doubler, Voltage Doubler Latour and Greinacher are shown. These differ mainly in the number of diodes and passive elements. Although Fig. 1 always presents capacitors between the source and the load, an inductor can also be used. This passive element is required to decrease the dispersion effect on the efficiency of the circuit [4]. 


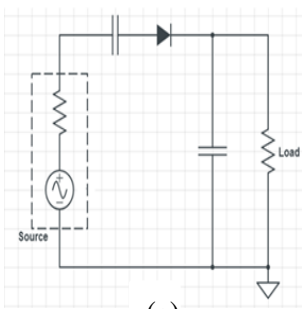

(a)

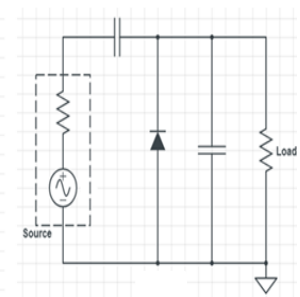

(b)

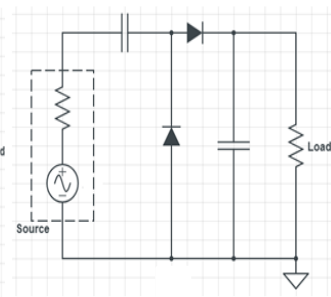

(c)

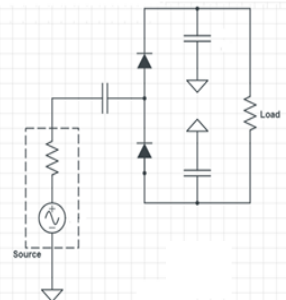

(d)

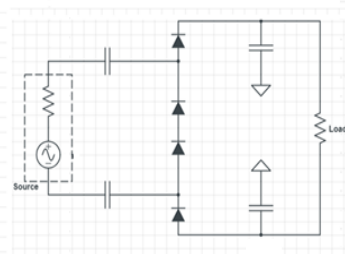

(e)

Fig. 1. Topologies of Rectifier Circuits: (a) Series, (b) Shunt, (c) Voltage Doubler, (d) Voltage Doubler Latour and (e) Greinacher.

The choice of the rectifier diode is crucial to obtain better performance and efficiency of the circuit. The series resistance $R_{S}$ and the diode junction capacitance $C_{j}$ are inversely related to the diode's efficiency. When $R_{S}$ increases, efficiency decreases due to resistive losses. The junction capacitance causes the same effect as it increases because it acts as a low-pass filter. These two parameters acting in parallel make the frequency a limiting factor of efficiency [10]. Another parameter that must be taken into account is the direct voltage drop in the diode, which should be as small as possible. The Schottky diodes with zero polarization are is the most suitable for the main rectifying component of the rectifier circuit because they present fast switching due to the metalsemiconductor junction that has low values of $R_{S}$ and $C_{j}$. In addition, these diodes provide a direct voltage drop as low as $150 \mathrm{mV}$, making them suitable for extremely low power levels. The HSMS285x and HSMS-286x Schottky diode series are the most commonly used in these conditions, since both have $C_{j}=0.18 p F$ and $R_{s}=25 \Omega$ and $R_{s}=5 \Omega$ respectively [11].

The internal resistances and capacitances of the diode give rise to mechanisms of losses in the rectifier circuit. High efficiency is desired in the rectifier circuit, but these mechanisms lower the efficiency [10]. The choice of diode should be made with caution, as its characteristics such as its threshold voltage, directly influence the efficiency of the rectifier. Parasitic effects can also cause significant decrease in efficiency, such as the resistance and diode junction capacitance. Another source of loss of this system is impedance matching because if the rectifier circuit is not properly coupled to its antenna, part of the incident energy will be reflected back into the environment and the power available for rectification will consequently be reduced. In addition, the traditional losses in the substrate and microstrip lines should also be considered as a limiting factor of the efficiency. Another phenomenon that can generate losses, especially at high frequencies, is the generation of harmonics. While providing a means to convert RF energy to DC, diode nonlinearities are also a source of loss because by operating the diode produces high frequency harmonics which reduces the amount of energy that is converted into DC.

An optimal level of efficiency corresponds to the compensation between harmonic generation, impedance matching, traditional losses and threshold voltage. These reasons point to the importance of an adequate choice of the rectifying diode and also to the need of the optimization process of this 
circuit, including as optimization variables the dimensions of the input and output filters of the system.

Increasing the efficiency of the rectifier circuit through loss control is a design challenge in the quest for high system efficiency. The electromagnetic energy harvesting system operates at high frequencies and, as it increases, the power available at a certain distance from the emitter decreases [12]. One tool to increase efficiency of the system is the optimization process which consists of the application of mathematical techniques to select the best candidates for solving a problem that achieves certain objectives. There are several optimization techniques that employ different algorithms. In the case of nonlinear circuits, such as the rectifier circuit, iterative algorithms that control the changes of the state variables of the nonlinear elements from one iteration to another can be used. But in some cases, in order to find an optimal response involving multiple objectives, it is necessary to solve a nonlinear system through optimization algorithms [13].

Conventional optimization methods as Gradient Decent algorithms are subject to local constraints and can perform poorly, and even fail, when the nature of the problem involves multimodalities, discontinuities, large search spaces or nonlinearities [14]. An alternative to overcome all these problems is the use of Genetic Algorithms, a technique based on the mechanisms of natural selection and genetics [15], which in these cases shows an effective way to find solutions close to the global optimum. This algorithm naturally deals with non-linear problems, which usually means that it is not possible to treat each parameter as an independent variable since the value of each optimization variable will affect the performance of the other variables.

\section{SIMULATION AND OPTIMIZATION}

With the increased frequency of operation of wireless applications in the last decade, new demands for printed circuit boards and laminated materials have emerged. The frequency characteristics of these materials have become one of the most critical design parameters in electronic applications [16]. Among the characteristics that most influence in this performance are the electrical permissiveness and the tangent of losses. In [5], the simulation was performed disregarding the properties of the board, so the connections between the components were treated as ideal. In [6], the substrate used was Rogers Duroid 5880, which has a relative permittivity equal to $\varepsilon_{r}=2.2$, while [7] used RO3006, a low loss material with $\varepsilon_{r}=6.15$ and [8] made use of a high efficiency dielectric that displays $\varepsilon_{r}=$ 10.2. These are good but expensive dielectrics for high frequencies applications. In this work, however, the rectifiers are manufactured with the substrate FR4 (Flame Retardant kind 4), the same applied in [9], which is widely used due to its low cost, despite presenting instability for microwave signals. Typically, for FR4, the electrical permittivity and dielectric loss tangent are provided by the manufacturers on the frequencies $1 \mathrm{MHz}, 100 \mathrm{MHz}$ and $1 \mathrm{GHz}$. It would be interesting, however, these properties be determined at higher frequencies so the designs could be simulated in a more realistic way. 
There are many methods to characterize dielectrics but none of them are trivial. The method used in this article is based on [17] and is able to determine these properties at any desired frequency. The method consists of the construction of a printed T-type resonator composed of a stub and a power line, both projected with the same impedance (Z), according to [17] and [18] respectively. The electrical permittivity is found through the dimensions of the resonator, the dielectric and the conductor of the plate used in its construction. The loss tangent is also calculated using some properties of the conductor and the measure of the parameter $S_{12}$ of the resonator. This method for the characterization of the dielectric was developed in order to minimize the effects of the SMA connectors used in the measurements so that they do not influence the response of the resonator $\mathrm{T}$.

Even though FR4 is not suitable for microwave signals, this material is very cheap and its use in this frequency range can be achieved with special modeling. The relative permittivity provided by the manufacturer of the material is 4.3 when the frequency is $1 \mathrm{MHz}$ but, unfortunately, the FR4 is not designed for the frequency of interest in this work, which is the ISM band. Thus, there is no guarantee that the parameters of FR4, when using at $2.45 \mathrm{GHz}$ frequency, would be those provided by the manufacturer. Therefore, the FR4 characterization at the ISM frequency band is necessary. This characterization was performed using the resonator T. The FR4 plate used in this work is $1.61 \mathrm{~mm}$ thick, covered on both sides by a $0.036 \mathrm{~mm}$ layer of copper. The T-resonator designed for this plate according to [17] and [18] is shown in Fig. 2 and has half-wavelength guided power line with width $w_{\text {line }}=3.0152 \mathrm{~mm}$, length $L_{\text {line }}=67.7319 \mathrm{~m}$ and impedance $Z_{\text {line }}=50 \Omega$ The stub's dimensions are: width $w_{s t u b}=1.7 \mathrm{~mm}$ and length $L_{s t u b}=51.9428 \mathrm{~mm}$. The dielectric characterization parameters for the $2.45 \mathrm{GHz}$ frequency are shown in Table II.

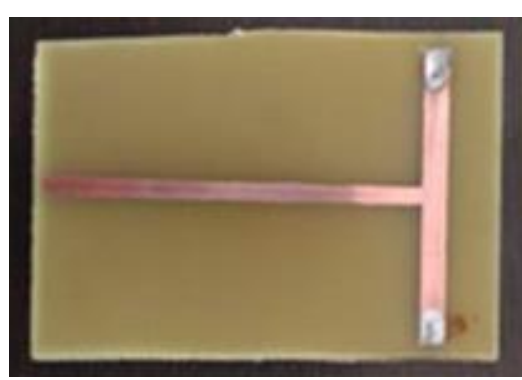

Fig. 2. T- resonator built in FR4 material.

TABLE II. STATE OF THE ART OF RECTIFIER CIRCUITS

\begin{tabular}{cc}
\hline Parameter & Value \\
\hline$\varepsilon_{\text {eff }}$ & 3.1465 \\
$\varepsilon_{r}$ & 4.3220 \\
$\tan (\delta)$ & 0.0325 \\
\hline
\end{tabular}

To check the validity of the parameters found, the T resonator was simulated in the ADS with the relative permittivity, effective permittivity of the plate and tangent loss shown in Table II. Fig. 3 shows the simulated and measured parameter $S_{12}$ for the FR4 plate, in which it is possible to note that up to $7 \mathrm{GHz}$ the behaviour of the measured and simulated curve are very close. Thereafter, there is a 
large dispersion between the measured and simulated graphs, proving that the FR4 material is not suitable for high frequencies.

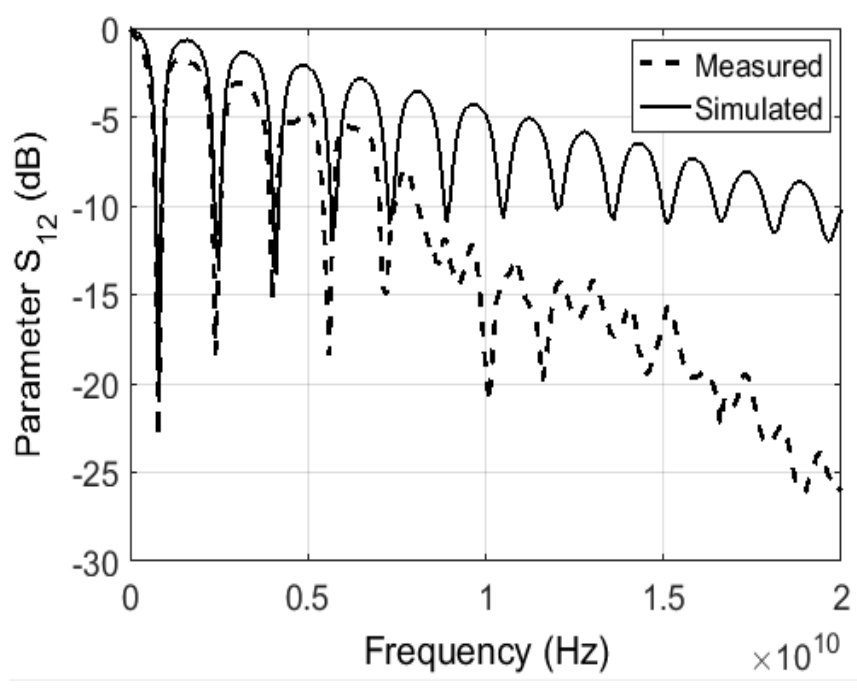

Fig. 3. Parameter $S_{12}$ of the T-ressonator on the FR4 board.

After the characterization of the dielectric, the optimization process was performed for the five topologies presented in Fig. 1. This process was performed in the Advanced Design System (ADS) software using the Genetic Algorithm. This algorithm is based on the mechanisms of natural selection and genetics, as Holland proposed in [15]. It codes the optimization variables in a set of bits. In the case of rectifier circuits, these variables are basically the passive elements and the dimensions of the input and output filters, although in some cases the input impedance and load will also play this role. The set of these discretized variables form the chromosomes, which grouped form the individual. The set of individuals form a population, where each one is a possible solution to the problem and are selected by probabilistic or even deterministic methods, in order to generate descendants, implementing the survival mechanism of the fittest. Genetic operators are responsible for the crossover and mutation processes, so a new population is created to replace the previous one. The new population is subjected to the same process and iteratively repeats, hoping that with each generation the quality of individuals will increase and the optimal solution or a good solution will be found. The Genetic Algorithm has proven to be the best choice for rectifier circuit optimization, as conventional methods are subject to trapping in minimal locations and can perform poorly and even fail when the nature of the problem involves multimodality, discontinuity, large search spaces or nonlinearity [14]. The Genetic Algorithm has applicability and robustness, proving to be an effective way to find solutions close to the global optimal since it usually deals with nonlinear problems, which usually means that it is not possible to treat each parameter as an independent variable.

This optimization process is multiobjective whose objectives are the rectified output voltage and the efficiency of the circuit. In addition, the output power is monitored to ensure that it is sufficient to power the load. The objectives were limited in different ways in each optimization process in order to achieve the highest efficiency rectified output voltage and 10000 generations were used. The input 
power of the rectifier is used as reference $P_{i n}=-15 \mathrm{dBm}$, although analysis at other powers are also performed for comparison purposes. Since this available electromagnetic radiation in the air comes from the electromagnetic waves of the ISM band, the operating frequency used in all cases is 2.45 $\mathrm{GHz}$. Table III shows the range of values that the optimization variables can assume in this work.

\begin{tabular}{cc}
\multicolumn{2}{c}{ TABLE III. OPTIMIZATION VARIABLES } \\
\hline Variable & Range of Values \\
\hline Microstrip length & $1 \mathrm{~mm}-100 \mathrm{~mm}$ \\
Microstrip width & $2 \mathrm{~mm}-25 \mathrm{~mm}$ \\
$\quad$ Inductor & $0.1 \mathrm{nH}-100 \mathrm{nH}$ \\
Capacitor & $0.1 \mathrm{pF}-100 \mathrm{pF}$ \\
$\quad$ Load & $1 \Omega-1 \mathrm{M} \Omega$ \\
Input Impedance & $1 \Omega-100 \Omega$ \\
\hline
\end{tabular}

The optimization process was performed for the HSMS 2850 and HSMS 2860 diodes for the Series, Shunt and Voltage Doubler topologies, being replaced by the HSMS 2852 and HSMS 2862 diodes in the Voltage Doubler Latour and Greinacher topologies. The latter differs from the first only because it contains two diodes in series on the same integrated circuit (IC) [11]. Table IV shows that for each type of the diodes, the optimization was performed when the load is fixed at $1 \mathrm{k} \Omega, 10 \mathrm{k} \Omega, 100 \mathrm{k} \Omega$, $1 \mathrm{M} \Omega$ and when the load is free, that is, it is an optimization variable that can assume values between $1 \mathrm{k} \Omega$ and $1 \mathrm{M} \Omega$. The optimization was also performed for fixed input impedance at $50 \Omega$ and variable impedance. In the later, the impedance is an optimization variable and can assume values between $10 \Omega$ and $100 \Omega$. This means that the antenna is not an $50 \Omega$ antenna or that we use an impedance transformer between the antenna and the input of the rectenna [19]. In addition to the Table IV, each process was performed with the passive element between the input filter and the diode as optimization variables, which may be a capacitor or an inductor.

Table V presents the best results of the optimization process for each of the topologies. The input impedance of the rectifier circuit is affected by the load value. Thus, both efficiency and output voltage will be dependent on this. By increasing the load value, the output voltage increases but the efficiency decreases. Thus, there is an optimal load value that balances this relationship and, after the optimization process for the presented circuits, it was determined that this value is $10 \mathrm{k} \Omega$. For topologies with inductive passive element, as Monodiode Serie, Voltage Doubler and Voltage Doubler Latour, the diode that best meets the requirements is the HSMS 2860 or 2862 and these have greater efficiencies than the circuits whose passive element is the capacitor and the diode is the HSMS 2850 or 2852, as Shunt and Greinacher. The higher efficiency found is $51.2 \%$ for the Monodiode Serie topology rectifier, a difference of $12.8 \%$ for the second highest efficiency rectifier, which is the Voltage Doubler Latour. This fact could easily be anticipated since the Series Rectifier Circuit contains only one diode, while the other topologies presented contain at least two. The use of only one 
diode provides smaller losses, especially considering the low rupture voltage of the diode used. This increases the efficiency of this topology. It must be remarked that the main objective is not to determine the best rectifier circuit topology, but to understand the influence of some process variables on the response of the different presented topologies.

TABLE IV. OPTIMIZATION PROCESSES

\begin{tabular}{ccc}
\hline Diode & $\boldsymbol{Z}_{\text {input }}[\boldsymbol{\Omega}]$ & Load $[\Omega]$ \\
\hline HSMS 285x & 50 & $1 \mathrm{k}$ \\
HSMS 285x & 50 & $10 \mathrm{k}$ \\
HSMS 285x & 50 & $100 \mathrm{k}$ \\
HSMS 285x & 50 & $1 \mathrm{M}$ \\
HSMS 285x & 50 & $1 k \leq$ load $\leq 1 M$ \\
HSMS 285x & $10 \leq Z_{\text {input }} \leq 100$ & $1 \mathrm{k}$ \\
HSMS 285x & $10 \leq Z_{\text {input }} \leq 100$ & $10 \mathrm{k}$ \\
HSMS 285x & $10 \leq Z_{\text {input }} \leq 100$ & $100 \mathrm{k}$ \\
HSMS 285x & $10 \leq Z_{\text {input }} \leq 100$ & $1 \mathrm{M}$ \\
HSMS 285x & $10 \leq Z_{\text {input }} \leq 100$ & $1 k \leq$ load $\leq 1 M$ \\
HSMS 286x & 50 & $1 \mathrm{k}$ \\
HSMS 286x & 50 & $10 \mathrm{k}$ \\
HSMS 286x & 50 & $100 \mathrm{k}$ \\
HSMS 286x & 50 & $1 \mathrm{M}$ \\
HSMS 286x & 50 & $1 k \leq$ load $\leq 1 M$ \\
HSMS 286x & $10 \leq Z_{\text {input }} \leq 100$ & $1 \mathrm{k}$ \\
HSMS 286x & $10 \leq Z_{\text {input }} \leq 100$ & $10 \mathrm{k}$ \\
HSMS 286x & $10 \leq Z_{\text {input }} \leq 100$ & $100 \mathrm{k}$ \\
HSMS 286x & $10 \leq Z_{\text {input }} \leq 100$ & $1 \mathrm{M}$ \\
HSMS 286x & $10 \leq Z_{\text {input }} \leq 100$ & $1 k \leq$ load $\leq 1 M$ \\
\hline
\end{tabular}

TABle V. Best Results of Optimization Process For EACH TOPOLOGY

\begin{tabular}{ccccccc}
\hline Topology & Diode HSMS & $\boldsymbol{Z}_{\text {input }}[\boldsymbol{\Omega}]$ & Load $[\boldsymbol{\Omega}]$ & $\boldsymbol{V}_{\text {out }}[\boldsymbol{V}]$ & $\boldsymbol{P}_{\text {out }}[\mu \boldsymbol{W}]$ & $\boldsymbol{\eta}$ \\
\hline Series & 2860 & 50 & $10 \mathrm{k}$ & 401.59 & 16.130 & $51.2 \%$ \\
Shunt & 2850 & 37.3 & $10 \mathrm{k}$ & 252 & 6.342 & $20.1 \%$ \\
Voltage Doubler & 2860 & 20.5 & $10 \mathrm{k}$ & 305 & 9.304 & $35.4 \%$ \\
Voltage Doubler Latour & 2862 & 50 & $10 \mathrm{k}$ & 495 & 11.513 & $38.4 \$$ \\
Greinacher & 2852 & 13.4 & $10 \mathrm{k}$ & 240 & 5.767 & $18.3 \%$ \\
\hline
\end{tabular}

\section{SENSITIVITY ANALYSIS}

Several parameters affect the response of a rectifier circuit, directly influencing its output voltage and efficiency. In order to understand how this happens, all the configurations that generated the results presented in Table $\mathrm{V}$ are analyzed, varying one parameter at a time and keeping the others constant. They were defined as tests-cases: input power, load, operating frequency, dimensions of the input filter, passive element, diode and output filter dimensions. This detailed analysis is performed with the purpose of understanding the operation of the circuit and how each of these variables influences the behavior of the circuit. In this way, it is also possible to determine which topology is best suited to operate under the conditions determined for the application of energy harvesting. 


\section{A. Test-case: Input Power}

To verify the influence of the input power on the rectifier circuit, the first step is to calculate the internal resistance of the rectifier circuit $\left(R_{S}\right)$ which is the resistance seen by the input source. To determine the internal resistance of the rectifier circuit, each of the topologies shown in Fig. 1 was simulated in the ADS software, using the high frequency diode models provided by the manufacturer and setting the capacitor or inductor to the operating frequency of $2.45 \mathrm{GHz}$. This was done because the diode curve is the exponential so the impedance seen by the input source varies nonlinearly with the input power. Therefore, it is not possible to model the entire circuit as a single linear equivalent circuit. Instead, the mathematical model must be obtained in two steps: from the source to the diode and from the diode to the load. First, the rectifier and load are considered perfectly matched so the maximum power transfer to the load is being performed. Knowing that power can be calculated as the product of voltage and current, in a graph involving these quantities, power is the area resulting from this multiplication. Thus, the highest power delivered to the load occurs at the midpoint of the current $\times$ voltage curve because it is where the resulting area is larger. Thus, the internal resistance of the rectifier circuit can be calculated by Ohm's Law at that point.

A current $\times$ load voltage simulation was performed for the input powers $-5 \mathrm{dBm},-10 \mathrm{dBm}$, $-15 \mathrm{dBm}$ and $-20 \mathrm{dBm}$, representing the available air power levels in the ISM band varying with the source distance. This was done for each of the topologies and the optimization processes were performed. The objective was to find the internal resistance of the rectifier circuit $\left(R_{S}\right)$ for each power when the load is fixed in $10 \mathrm{k} \Omega$. The value found in the optimization process for all topologies is shown in Table VI. Fig. 4 shows the current $x$ load voltage simulation graphs for the Series and Shunt topologies. The other topologies have the same behavior pattern and the calculation of the internal resistance of the rectifier circuit for them is performed in the same way.

TABLE VI. INTERNAL RESISTANCE OF THE RECTIFIER CiRCUITS

\begin{tabular}{cccccc}
\hline $\mathbf{P}_{\text {out }}[\mathbf{d B m}]$ & Series & Shunt & $\begin{array}{c}\text { Voltage } \\
\text { Doubler }\end{array}$ & $\begin{array}{c}\text { Voltage } \\
\text { Doubler } \\
\text { Latour }\end{array}$ & Greinacher \\
\hline-20 & $12.65 k \Omega$ & $4.7167 k \Omega$ & $19.132 k \Omega$ & $50.773 k \Omega$ & $24.1160 k \Omega$ \\
-15 & $5.5773 k \Omega$ & $3.2098 k \Omega$ & $7.0259 k \Omega$ & $17.648 k \Omega$ & $16.2590 k \Omega$ \\
-10 & $2.9457 k \Omega$ & $2.0591 k \Omega$ & $3.6518 k \Omega$ & $8.8835 k \Omega$ & $9.2992 k \Omega$ \\
-5 & $2.3360 k \Omega$ & $2.1743 k \Omega$ & $2.2374 k \Omega$ & $6.9841 k \Omega$ & $7.6829 k \Omega$ \\
\hline
\end{tabular}

The internal resistance of the circuit varies with the input power of the circuit, that is, there will be an impedance shift when the power changes. The rectifier circuit is designed for a given incident power and, in turn, the impedance matching is realized for that power. Since it is not possible to determine accurately the available electromagnetic radiation in the air, the performance of the rectifier circuit will undergo constant variation. It will also vary the efficiency of any wireless power harvesting system. The efficiency of each of the circuits was simulated when there is variation of the load. Table VII shows the load $R_{\max }$ for which each topology has higher efficiency $\eta_{\max }$ at different Brazilian Microwave and Optoelectronics Society-SBMO received 23 Aug 2019; for review 29 Aug 2019; accepted 25 Jan 2020 $\begin{array}{llll}\text { Brazilian Society of Electromagnetism-SBMag } & \text { (C) 2020 SBMO/SBMag } & \text { (cc) BY } & \text { ISSN 2179-1074 }\end{array}$ 
powers.

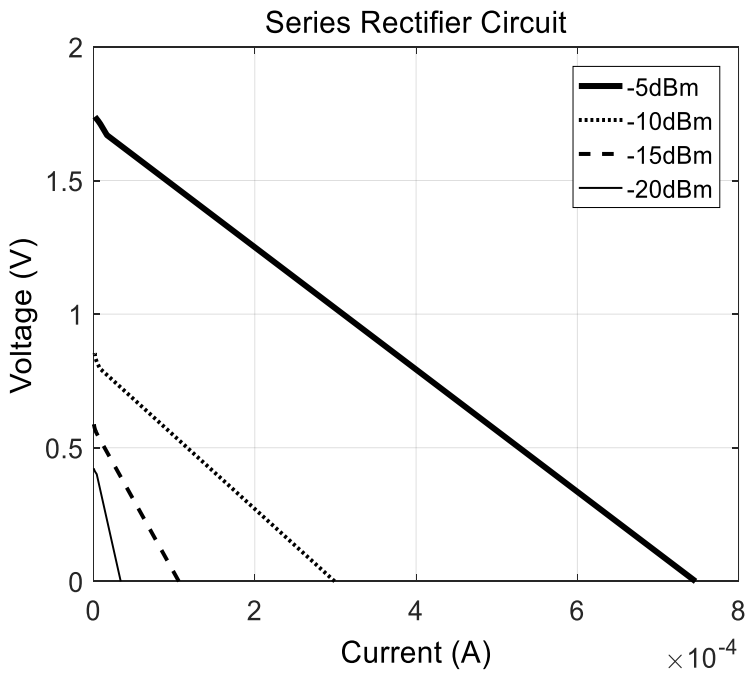

(a)

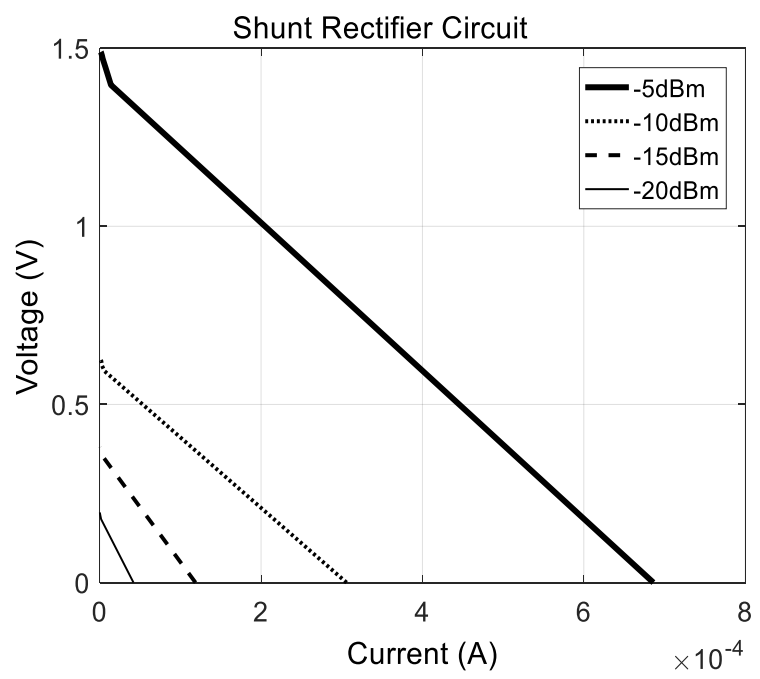

(b)

Fig. 4. Current x Load Voltage: (a) Series Rectifier and (b) Shunt Rectifier.

TABLE VII. MAXIMUM EFFICIENCY LOAD

\begin{tabular}{|c|c|c|c|c|c|}
\hline Topology & $\mathbf{P}_{\text {in }}$ & $-20 \mathrm{dBm}$ & $-15 \mathrm{dBm}$ & $-10 \mathrm{dBm}$ & $-5 \mathrm{dBm}$ \\
\hline \multirow[t]{2}{*}{ Series } & $\mathrm{R}_{\max }$ & $5.6 k \Omega$ & $10 \mathrm{k} \Omega$ & $5 k \Omega$ & $2.33 k \Omega$ \\
\hline & $\eta_{\max }$ & $18.15 \%$ & $51.2 \%$ & $55.74 \%$ & $62.25 \%$ \\
\hline \multirow[t]{2}{*}{ Shunt } & $\mathrm{R}_{\max }$ & $5 k \Omega$ & $4 k \Omega$ & $2 k \Omega$ & $2 k \Omega$ \\
\hline & $\eta_{\max }$ & $13.32 \%$ & $23.1 \%$ & $36.65 \%$ & $40.97 \%$ \\
\hline \multirow[t]{2}{*}{ Voltage Doubler } & $\mathrm{R}_{\max }$ & $50 k \Omega$ & $10 \mathrm{k} \Omega$ & $4 k \Omega$ & $2 k \Omega$ \\
\hline & $\eta_{\max }$ & $15.04 \%$ & $35.4 \%$ & $46.61 \%$ & $46.77 \%$ \\
\hline \multirow[t]{2}{*}{ Voltage Doubler Latour } & $\mathrm{R}_{\max }$ & $100.2 k \Omega$ & $21.3 \mathrm{k} \Omega$ & $10.4 k \Omega$ & $4.93 k \Omega$ \\
\hline & $\eta_{\max }$ & $20.66 \%$ & $38.88 \%$ & $45.42 \%$ & $47.52 \%$ \\
\hline \multirow[t]{2}{*}{ Greinacher } & $\mathrm{R}_{\max }$ & $20 k \Omega$ & $15 k \Omega$ & $10 \mathrm{k} \Omega$ & $5 k \Omega$ \\
\hline & $\eta_{\max }$ & $9.25 \%$ & $19.21 \%$ & $31.73 \%$ & $40.42 \%$ \\
\hline
\end{tabular}

The maximum power transfer must occur when the internal resistance of the circuit is equal to the load since in this condition the power is equally distributed between the two resistors. For input power $-15 \mathrm{dBm}$, theoretically, the circuit should be matched to the power input impedance representing the antenna. However, this match is not perfect. Observing Tables VI and VII, it is noted that for this input power the internal resistance of the circuit is close to the resistance that offers greater efficiency for all topologies. The difference between the two resistors can be explained by the impedance matching between source and circuit, which is not perfect. For the other efficiencies, the circuit is unmatched since it was only optimized for $-15 \mathrm{dBm}$. The variation of the internal resistance of the circuit when there is variation of incident power, shown in Table VI, proves that when the incident power varies, the impedance matching is broken and, for that reason, this relationship cannot be made.

\section{B. Test-case: Load}

To observe the influence of the load on the rectifier circuit, the input power and frequency were kept constant at $-15 \mathrm{dBm}$ and $2.45 \mathrm{GHz}$ while there is load variation. The observed parameter is the output voltage. 
Fig. 5 shows the relationship between the load and the output voltage of the rectifier. It can be seen that the output voltage increases with the load. However, when the load reaches high values the output voltage begins to saturate. This happens because the power delivered to the load decreases due to the decreased efficiency.

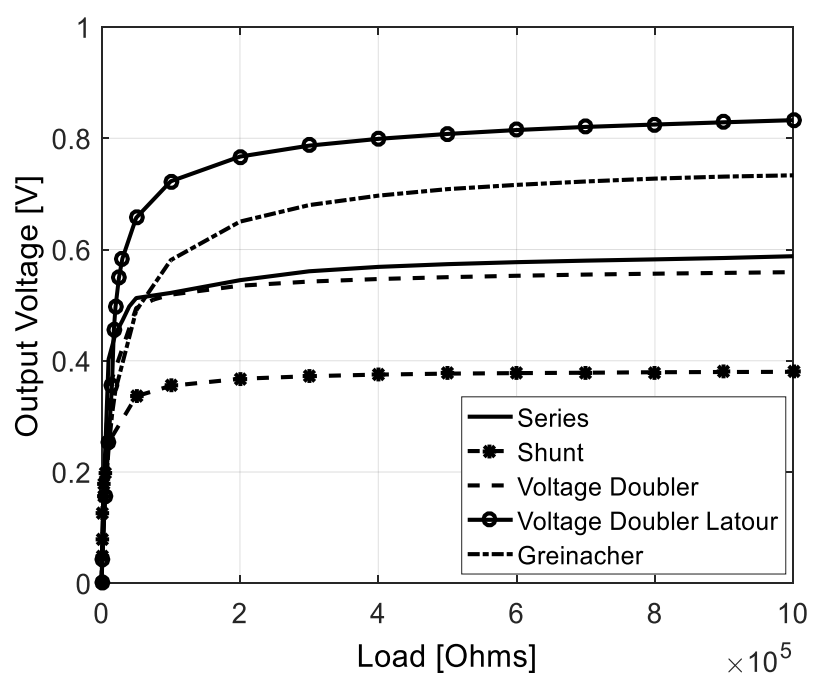

Fig. 5. Load x Output Voltage.

During the optimization process for the $100 \mathrm{k} \Omega$ and $1 \mathrm{M} \Omega$ loads this phenomenon could already be observed because, although it is fed with a high voltage, the power over the load is small, causing the circuit to have low efficiency. The load must be chosen in order to provide the highest output voltage and output power to ensure that the efficiency of the circuit is not small. Through the optimization process it has been determined for all topologies that the optimum load is $10 \mathrm{k} \Omega$. In all cases, this value is less than the value of the load that makes the voltage saturate, which is between $50 \mathrm{k} \Omega$ and $100 k \Omega$ for all topologies.

\section{Test-case: Frequency}

The rectifier circuits were optimized to operate at $2.45 \mathrm{GHz}$. Fig. 6 shows the output voltage when the frequency varies. In this case, the load is determined in the optimization process and is $10 \mathrm{k} \Omega$ at input power of $-15 \mathrm{dBm}$.

For all topologies, the output voltage is maximum at the optimization frequency and deteriorates as it moves away from it. This fact was already expected, since the impedance matching at $-15 \mathrm{dBm}$ was performed for this frequency. Another important fact to note is that all rectifier circuits have very narrow band making the lower frequency variation have a great impact on the performance of the rectifier. 


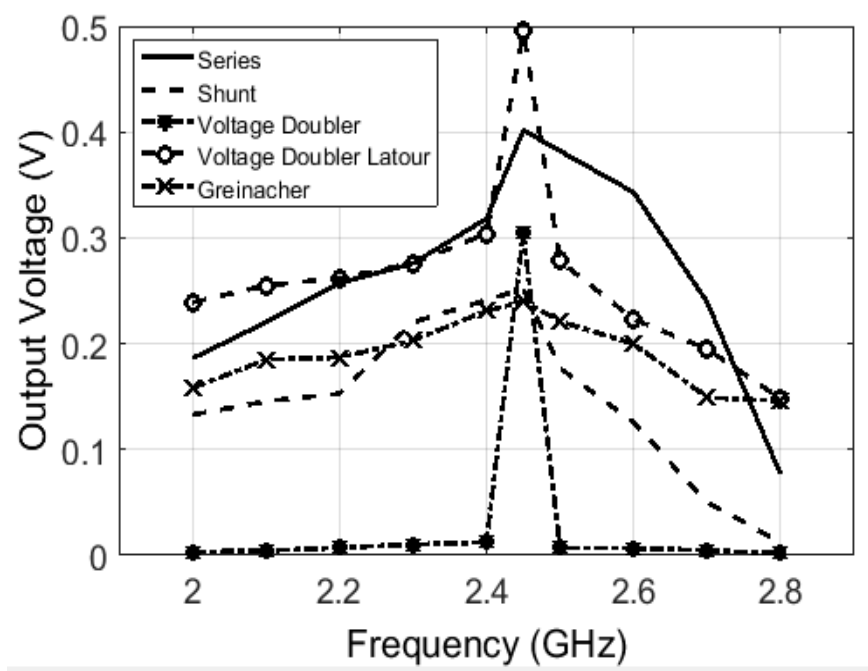

Fig. 6. Frequency x Output Voltage.

\section{Test-case: Dimensions of the Input Filter}

The input filter is a stub with widths and position determined through the optimization process.

Table VIII shows the impedance of the source and the measured circuits for each of the topologies. The perfect impedance match occurs when these impedances are equal. It can be noted that the best impedance matching happens for the Series topology, although it is not perfect. The fact that there is no match of perfect impedance in the circuits found by the optimization certainly affects the efficiency of these. Nevertheless, the circuits show good performance.

TABLE VIII. IMPEDANCE OF THE CIRCUITS

\begin{tabular}{cccccc}
\hline & Series & Shunt & Voltage Doubler & Voltage Doubler & Greinacher \\
& {$[\Omega]$} & {$[\Omega]$} & {$[\Omega]$} & Latour $[\Omega]$ & {$[\Omega]$} \\
\hline$Z_{\text {source }}$ & 50 & 37.34 & 20.787 & 50 & 13.42 \\
$Z_{\text {circuit }}$ & $57.45-j 2.00$ & $43.19+j 2.52$ & $24.17-j 19.91$ & $33.45+j 9.61$ & $14.31-j 0.17$ \\
\hline
\end{tabular}

\section{E. Test-case: Passive Element}

The passive element, which may be a capacitor or an inductor between the input filter and the diode, has the function of aiding the impedance matching and thus reducing the scattering effects of the rectifier circuit. In addition, by adding this element to the circuit, the degree of freedom for the optimizer has been increased since this element is a new optimization variable. Considering that the impedance of the rectifier circuits is affected by the dimensions of the tracks and sections, the total impedance seen by the source and load may change from a slightly inductive to a slightly capacitive behavior when the optimization of these dimensions is performed. There are several combinations of the passive element - capacitor or inductor - and the dimensions of the tracks and sections that meet the optimization objectives resulting in the same output voltage and efficiency. The combinations found in these optimization processes, however, seek not only higher rectifier efficiency and output 
voltage, but also limit track dimensions to obtain reasonable dimensions for the complete rectifier circuit.

Through the optimization process, it was determined that the Series, Voltage Doubler and Voltage Doubler Latour topologies present better performance when the passive element is the inductor and Parallel and Greinacher circuits are better with the capacitor, when combined with the dimensions of the tracks and sections found in the optimization process. Fig. 7 shows the behaviour of the circuit when the inductance and capacitance vary. When the passive element is the inductor, a pattern is observed in the behaviour of the output voltage and efficiency of the circuits. They have a high value for a very specific inductance and decrease considerably as it moves away from the ideal for both a higher and a lower value. The ideal inductance values are $12.38 \mathrm{nH}, 1 \mathrm{nH}$ and $7.38 \mathrm{nH}$ for Series, Voltage Doubler and Voltage Doubler Latour topologies, respectively. These values are exactly the same as those found in the optimization process. For Shunt topology, whose passive element is the capacitor, the output voltage and efficiency increase along with the capacitance until it reaches the value of $1 p F$. After this value, the output quantities remain constant. For the Greinacher type rectifier there was no change in the output with the capacitance variation.

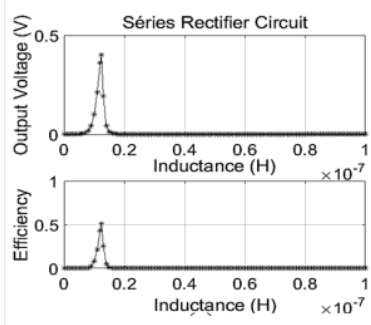

(a)

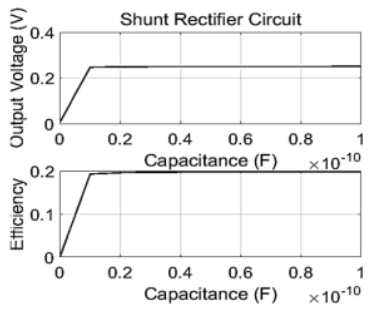

(b)

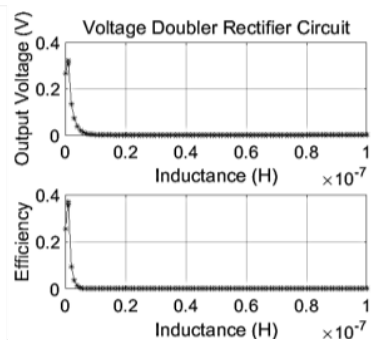

(c)
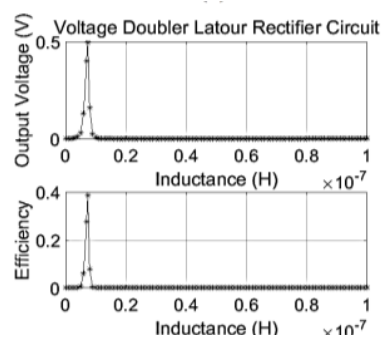

(d)

Fig. 7. Influence of the Passive Element on the Rectifier Circuit: (a) Series Rectifier, (b) Shunt Rectifier, (c) Voltage Doubler Rectifier and (d) Voltage Doubler Latour Rectifier.

\section{F. Test-Case: Diode}

The diode has great importance in the performance of the rectifier circuit. The family of Schottky diodes HSMS 285-x has higher resistance in series and therefore offers greater resistive loss. It has lower activation voltage which means it needs less voltage at its terminals to drive than the HSMS 286- $\mathrm{x}$ [11]. Table IX, it is shown the efficiency, voltage and load power for different diodes when the input power is $P_{i n}=-15 \mathrm{dBm}$ and the load is $10 \mathrm{k} \Omega$ found by the optimization process.

Table IX shows that in Voltage Doubler Latour and Greinacher topologies these diodes have been replaced by HSMS 2852, 285C, 2862 and 286C integrated circuits respectively containing two HSMS 2850, 285B, 2860 and 286B diodes in series [11].

Each of the topologies, as expected, obtained better performance for the diodes for which they were optimized. The change of diode causes the output voltage and efficiency of the rectifier to undergo major changes. Another fact that can be observed in Table IX is that for the Series, Voltage Doubler and Voltage Doubler Latour topologies whose inductor is the element responsible for decreasing the 
dispersion effect on the efficiency of the circuit, the HSMS 2860 or 2862 diodes present better performance than HSMS 2850 or 2852 diodes. The same happens with the HSMS 286B or 286C diodes in relation to the HSMS 285B or 285C diodes. As for the topologies Shunt and Greinacher, which has the capacitor as a passive element to decrease the dispersion, the opposite happens, and the HSMS 2850 or 2852 diodes present better results than the HSMS 2860 or 2862 diodes, whereas the HSMS 285B or $285 \mathrm{C}$ better performance than HSMS 286B or $286 \mathrm{C}$ diodes.

TABLE IX. INFLUENCE OF THE DiOdE ON THE ReCTIFIER CiRCUIT

\begin{tabular}{ccccc}
\hline & Diode HSMS & $\mathbf{V}_{\text {in }}[\mathbf{m V}]$ & $\mathbf{P}_{\text {in }}[\boldsymbol{\mu W}]$ & $\boldsymbol{\eta}$ \\
\hline Series & 2850 & 317.8 & 10.0997 & $32.11 \%$ \\
& $285 B$ & 260.4 & 6.9726 & $22.07 \%$ \\
Shunt & 2860 & 402.4 & 16.197 & $51.25 \%$ \\
& $286 B$ & 297.3 & 8.8391 & $28.01 \%$ \\
& 2850 & 252.0 & 6.3423 & $20.18 \%$ \\
& $285 B$ & 217.0 & 4.4855 & $16.17 \%$ \\
Voltage Doubler & 2860 & 156.0 & 2.4275 & $9.79 \%$ \\
& $286 B$ & 212.0 & 4.7410 & $15.58 \%$ \\
& 2850 & 286.6 & 8.2135 & $25.9 \%$ \\
& $285 B$ & 250.5 & 6.2740 & $19.81 \%$ \\
Voltage Doubler Latour & 2860 & 347.7 & 12.2341 & $38.7 \%$ \\
& $286 B$ & 320.7 & 10.2902 & $32.6 \%$ \\
& 2850 & 411.0 & 7.9467 & $25.1 \%$ \\
& $285 B$ & 330.9 & 5.1502 & $16.3 \%$ \\
Greinacher & 2860 & 512.0 & 12.3325 & $39 \%$ \\
& $286 B$ & 375.6 & 6.6380 & $21 \%$ \\
& 2850 & 240.0 & 5.7880 & $18.3 \%$ \\
& $285 B$ & 236.0 & 5.5820 & $17.65 \%$ \\
& 2860 & 164.0 & 2.6860 & $8.48 \%$ \\
& $286 B$ & 160.0 & 2.5680 & $8.13 \%$ \\
\hline
\end{tabular}

\section{G. Test-Case: Dimensions of the Output Filter}

The main function of the output filter is to remove the harmonics from the diode caused by its nonlinarites. This filter is formed by two lines of microstrip and a capacitor in parallel between them. In addition, the capacitor coupled to the filter has the function of storing the voltage that is delivered to the load. The dimensions of this filter were determined through the optimization process and the way they influence the output voltage and efficiency of the Series, Shunt, Voltage Doubler, Voltage Doubler Latour and Greinacher is presented.

Fig. 8 shows the Parameter $S_{21}$ of this filter for the Series and Shunt topologies when they present the dimensions found by the optimization process. The purpose is to analyse the operation of this filter.

In Fig. 8, it is estimated as a safety parameter that the signal power can drop in half. It can be seen as a non-signal filtering up to $-3 d B$. Thus, any signal less than $-3 d B$ returns to the diode so that the harmonics are rectified. For the DC component of the rectified signal the gain is the unity which means that this signal reaches the load unchanged. In this way, the Series topology filter does not filter out some harmonics. This problem does not occur for the Shunt topology filter since all frequency components presents in the signal are below $-3 d B$ and therefore are definitely filtered. In fact, since only the DC component is transmitted, Fig. 8(b) only a very low amplitude numerical error 
of the simulation process without representing a real non-transmitted power. The analysis can be performed in the same way for the other topologies.

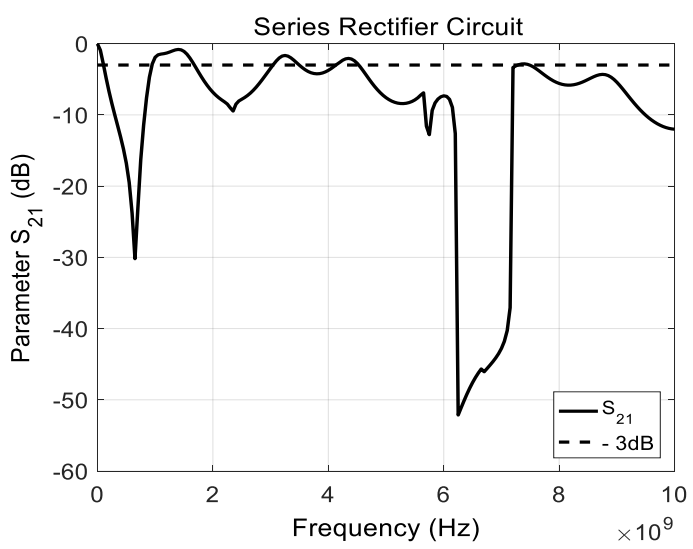

(a)

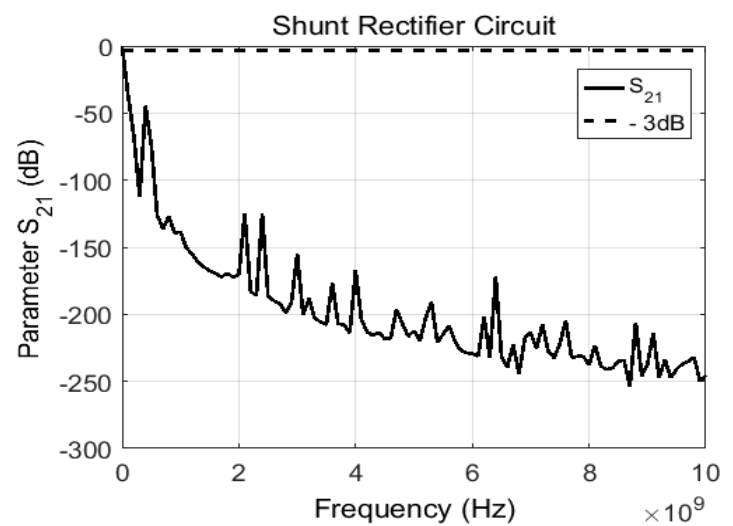

(b)

Fig. 8. Parameter $S_{21}$ of Output Filter: (a) Series Rectifier and (b) Shunt Rectifier.

The filter dimensions that provide the highest output voltage and efficiency are very close to the dimensions found in the optimization process and therefore the Parameter $S_{21}$ of the filter when the dimensions assume these values does not change, maintaining the proper operation of the filter. The capacitor coupled to this filter has only the function of storing voltage to supply the load and its value has no effect on the output of the rectifier circuits.

\section{RECTIFIER CIRCUIT FOR APPLICATION OF WIRELESS ENERGY TRANSMISSION AND ENERGY HARVESTING}

The analysis of all rectifier circuit topologies provides not only the understanding of how each variable affects the response of the circuit, but also helps in choosing the topology to be used for application of wireless energy transmission and energy harvesting. The Figure of Merit is defined as the standard product of the output voltage of the rectifier by its energy efficiency. Fig. 9 presents the Figure of Merit as a function of input power for different topologies.

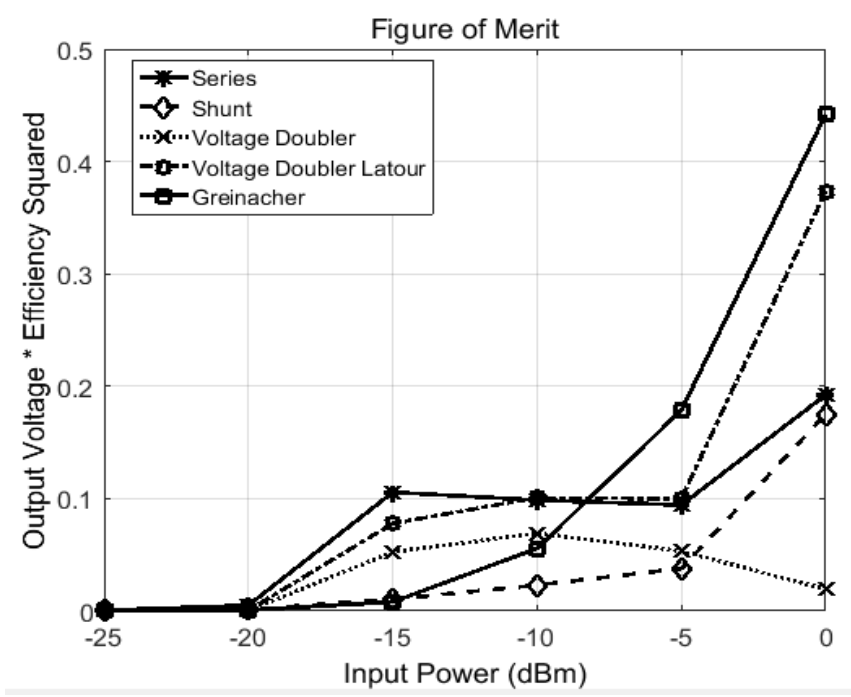

Fig. 9. Figure of Merit: Characterization of the Performance of Different Topologies of Rectifier Circuits. 
Although the characterization of the Figure of Merit utilizes the output voltage and efficiency, the latter is the most desired feature for a rectifier circuit in a rectenna, and therefore this magnitude is squared. In this way a greater weight was given to the magnitude of the efficiency in the Figure of Merit. To accomplish that the input power was ranged from $-25 \mathrm{dBm}$ to $0 \mathrm{dBm}$ while the output voltage was multiplied by the square of the efficiency. Looking at the Figure of Merit, it is possible to realize that in the input power $-15 \mathrm{dBm}$, for which the circuits have been optimized, the rectifier circuit that best meets the necessary requirements is the Series topology. It is possible to realize that, among all curves, the curve of the series topology presents, in this input power, the largest Figure of Merit which represents a good balance between high efficiency and high voltage output keeping the rectifier dimensions reasonable. Also, the series topology provides even better performance as the input power decreases to $-20 \mathrm{dBm}$ or increases to $-10 \mathrm{dBm}$ in order to take into account the fact that the available electromagnetic radiation in the air is very low and not constant. In this way, the Series Rectifier Circuit is the one chosen for the application of wireless electromagnetic radiation harvesting.

The dimensions determined through the optimization process of this circuit are shown in Fig. 10. Table $\mathrm{X}$ shows the definition of the other process optimization variables.

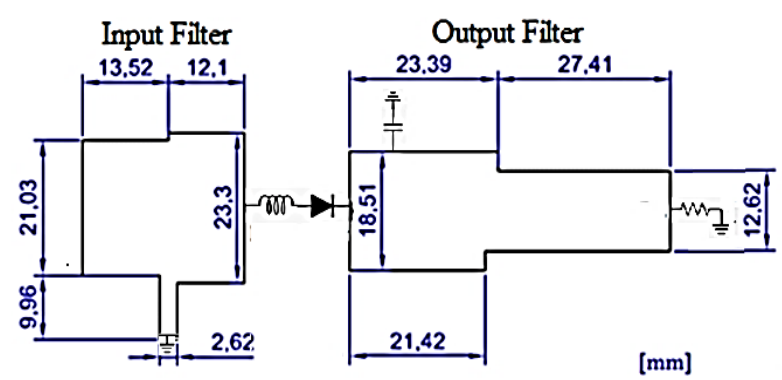

Fig. 10. Dimensions Series Rectifier Circuits.

Table X. VAlues of the Optimization for the Series Rectifier Circuits

\begin{tabular}{cc}
\hline Variable & Range of Values \\
\hline Diode & HSMS 2860 \\
Impedance & $50 \Omega$ \\
Inductor & $12.37 \mathrm{nH}$ \\
Capacitor & $0.1 \mathrm{pF}-100 \mathrm{pF}$ \\
Load & $10 \mathrm{k} \Omega$ \\
\hline
\end{tabular}

\section{A. Modeling and Transfer Function of Series Rectifier}

The Series Rectifier Circuit was modeled as an RLC (Resistor, Inductor and Capacitor) circuit in order to find a transfer function relating output voltage and input to it. The modeling was divided into two parts: input filter with the passive element and output filter with the load.

A two-terminal microstrip section can be modeled as an Inductor-Capacitor (LC) circuit [20]. Fig. 11(a) shows the LC circuit corresponding to this section. For the modeling of the input filter it was divided into four sections of microstrips, as shown in Fig. 11(b). The sections have different widths 
and lengths which can be seen in Table XI together with the impedance of each of them calculated [21]. As shown in Fig. 11(b), there is a difference in width between two adjacent microstrips. This junction must also be modeled as an LC circuit.

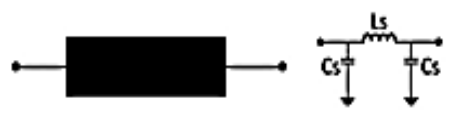

(a)

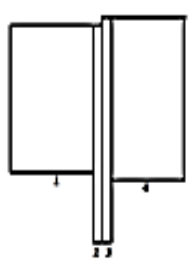

(b)

Fig. 11. Modeling of Microstrip: (a) LC Circuit corresponding to a Microstrip Segment [20] and (b) Input Filter divided into Microstrip.

TAble XI. Dimensions of the Microstrip that Make Up the InPUT Filter

\begin{tabular}{ccccc}
\hline Microstrip & $\mathbf{1}$ & $\mathbf{2}$ & $\mathbf{3}$ & $\mathbf{4}$ \\
\hline Width $[\mathrm{mm}]$ & 21.033 & 30.997 & 32.129 & 23.298 \\
Length $[\mathrm{mm}]$ & 12.205 & 1.311 & 1.311 & 10.794 \\
Impedance $[\Omega]$ & 12.824 & 9.180 & 8.895 & 11.758 \\
\hline
\end{tabular}

Fig. 12 shows the LC circuit corresponding to this difference in width between the microstrips. The values of the inductances and the capacitance are calculated according to [20]. Although these calculations are preferentially applied when the step is symmetrical, they can be used for asymmetric steps like those in Fig. 11(b).
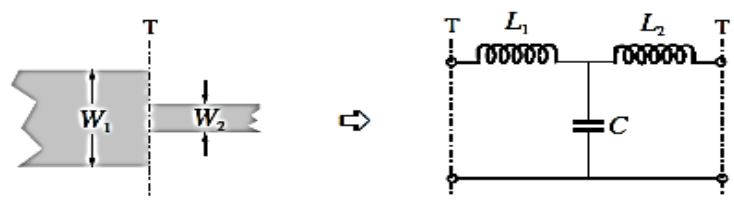

Fig. 12. LC Circuit Corresponding to the Step Width between the Microstrip Sections [21].

Through simulation tests, it was found that the modeling shown in Fig. 11(a) is efficient when the width of the microstrip is as small as $w \leq 3 \mathrm{~mm}$. From Table XI it can be seen that microstrips 1 and 4 do not meet this requirement. In this work till using the simulation feature, it was determined that these microstrips can be represented by adding a resistance in series with the inductance, as shown in Fig. 13(a). The capacitance $C_{S}$ continues to be calculated as in [20] and the inductance $L_{S}$ and the resistance $R_{S}$ are determined through an optimization process, also using the Genetic Algorithm. The input filter also contains a terminal connected to the ground plane. From Fig. 11(a) it is observed that the terminals of the microstrip line are modeled as the capacitors $C_{S}$, whereas the line itself is represented by the inductor $L_{S}$.

In this sense, since the filter terminal is in the ground plane, this capacitor will have its two terminals grounded and, therefore, need not be considered in this modeling.

Although Fig. 10 shows that there is a large step in the output filter, it was modeled as a single microstrip, represented by resistance $\left(R_{S}\right)$ in series with the inductor $\left(L_{S}\right)$. It also presents three 
terminals, each represented by a capacitor in the model of Fig. 13 (b): the filter input terminal $\left(C_{s 1}\right)$, the filter output terminal $\left(C_{s 2}\right)$ and the terminal where the charge storage capacitor is coupled $\left(C_{\text {terminal }}\right)$. The $C_{\text {otm }}$ capacitor is the charge storage capacitor that was found in the process of optimizing the Series Rectifier Circuit. All values of the elements that make up this RLC circuit were determined by the optimization process, as described for input filters 1 and 4 .

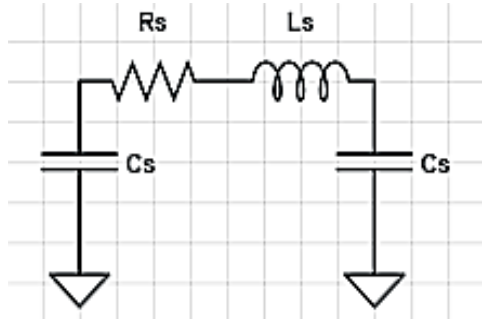

(a)

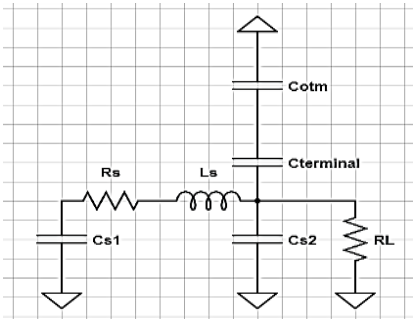

(b)

Fig. 13. Modeling for Microstrip with width $w>3 \mathrm{~mm}$ and (b) Output Filter modeled as RLC Circuit.

Since the output filter is located after the diode, it can be considered that this filter is fed only with DC voltage, being optimized to operate in this condition. Thus, the modeling was performed only for the DC voltage present at the cathode of the diode, but other frequencies can make up this signal. Thus, it is necessary to perform the Fourier Transform on the voltage after the diode to verify what these frequencies are and to sum to the final voltage the sum of the voltages referring to each of these frequencies when necessary.

Using the modeling shown in Fig 11, Fig 12 and Fig.13 and, knowing that the modeled sections are in series, the RLC circuit that represents the model of the rectifier circuit is shown in Fig. 14 and Table XII shows the values of the capacitors, inductors and resistors of the modeled rectifier circuit. Each part of Fig. 14 is a microtrip section represented by lumped parameters. The model was obtained segment by segment for the input filter (from the source to the diode) and for the output filter (from the diode to the load). Fig. 14 shows the junction of all the sections modeled on a single circuit that can be simulated in SPICE and its transfer function can be obtained by separating the filter analysis (without using the diode). For the validation of the modeling, the operating frequency $2.45 \mathrm{GHz}$ and input power $-15 \mathrm{dBm}$ were used in the simulation of the microstrip circuit and the RLC circuit.

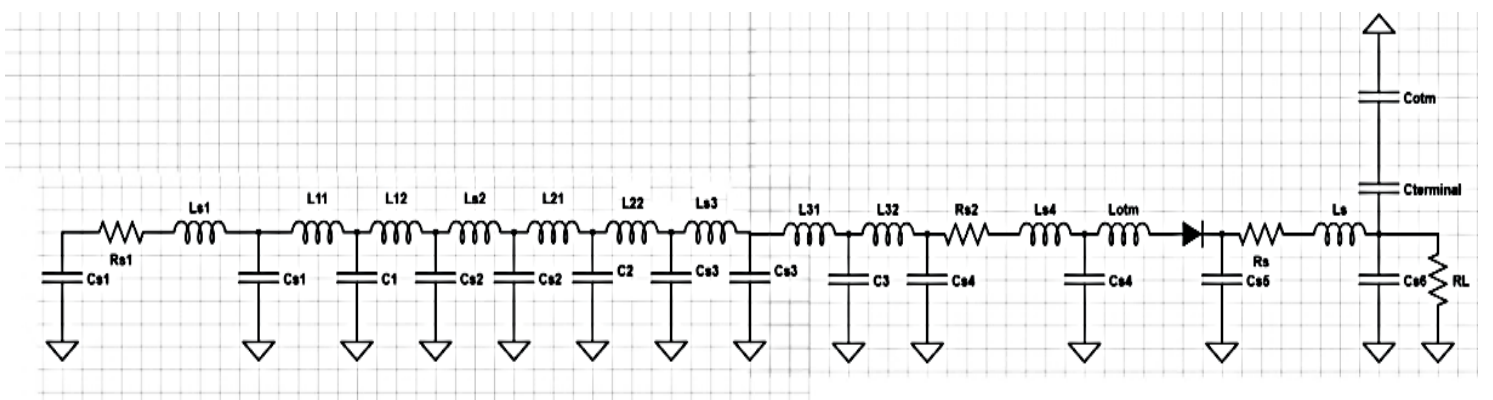

Fig. 14. Series Rectifier Circuit modeled as RLC Circuit. 
Table XIII shows the voltage and output power and efficiency of the rectifier circuit in both conditions. The proximity between the values validates the modeling. The transfer function is divided into two parts: the input filter and the output filter. The diode cannot be included in this case because of its non-linearity characteristic.

Table XII. Values of the Elements of the Modeling Series Rectifier Circuits

\begin{tabular}{ccc}
\hline Inductor $[\mathbf{n H}]$ & Capacitor $[\mathbf{p F}]$ & Resistance $[\Omega]$ \\
\hline $\mathrm{L}_{\mathrm{s} 1}=0.8292$ & $\mathrm{C}_{\mathrm{s} 1}=3.1520$ & $\mathrm{R}_{\mathrm{s} 1}=0.5656$ \\
$\mathrm{~L}_{\mathrm{s} 2}=0.0711$ & $\mathrm{C}_{\mathrm{s} 2}=0.4235$ & $\mathrm{R}_{\mathrm{s} 2}=1.0313$ \\
$\mathrm{~L}_{\mathrm{s} 3}=0.0689$ & $\mathrm{C}_{\mathrm{s} 3}=0.4370$ & $\mathrm{R}_{\mathrm{s}}=0.000022$ \\
$\mathrm{~L}_{\mathrm{s} 4}=0.7293$ & $\mathrm{C}_{\mathrm{s} 4}=2.9630$ & $\mathrm{R}_{\mathrm{L}}=10000$ \\
$\mathrm{~L}_{11}=1.42 \times 10^{-7}$ & $\mathrm{C}_{\mathrm{s} 5}=55.2865$ & \\
$\mathrm{~L}_{12}=1.01 \times 10^{-7}$ & $\mathrm{C}_{\mathrm{s} 6}=-4.9241$ & \\
$\mathrm{~L}_{21}=8.11 \times 10^{-10}$ & $\mathrm{C}_{1}=1.168 \times 10^{-6}$ & \\
$\mathrm{~L}_{22}=7.85 \times 10^{-10}$ & $\mathrm{C}_{2}=9.122 \times 10^{-8}$ & \\
$\mathrm{~L}_{31}=3.95 \times 10^{-8}$ & $\mathrm{C}_{3}=6.871 \times 10^{-7}$ & \\
$\mathrm{~L}_{32}=5.23 \times 10^{-8}$ & $\mathrm{C}_{\text {terminal }}=0.9146$ & \\
$\mathrm{~L}_{\mathrm{otm}}=12.38$ & $0.1 \leq \mathrm{C}_{\mathrm{otm}} \leq 100$ & \\
$\mathrm{~L}_{\mathrm{s}}=-0.9215$ & & \\
\hline
\end{tabular}

Table XIII. Test do Validate the Modeling of the Complete Rectifier Circuits

\begin{tabular}{cccc}
\hline- & $\mathbf{V}_{\text {out }}$ & $\mathbf{P}_{\text {out }}$ & Efficiency \\
\hline Microstrip & $402 \mathrm{mV}$ & $16.13 \mu \mathrm{W}$ & $51.3 \%$ \\
Modeling & $397.6 \mathrm{mV}$ & $15.809 \mu \mathrm{W}$ & $50.82 \%$
\end{tabular}

The transfer function is calculated by the ratio of the load voltage to the input voltage of the rectifier circuit. For both filters, the transfer functions were determined.

The transfer function of the input filter is given by (1).

$$
H_{\text {FilterIn }}=\frac{R_{L}}{\text { den }}
$$

where den is given by (2).

$$
\begin{aligned}
& \operatorname{den}=\mathrm{R}_{\mathrm{L}}+\mathrm{L}_{11} \mathrm{~s}+\mathrm{L}_{3} \mathrm{~S}+\mathrm{L}_{5} \mathrm{~s}+\mathrm{L}_{7} \mathrm{~s}+\mathrm{L}_{9} \mathrm{~S}+\frac{\mathrm{R}_{2}+\frac{1}{\mathrm{C}_{11} \mathrm{~S}}+\mathrm{L}_{10} \mathrm{~S}}{\mathrm{C}_{10} \mathrm{~s}+\left(\mathrm{R}_{2}+\frac{1}{\mathrm{C}_{10} \mathrm{~S}}+\frac{1}{\mathrm{C}_{11} \mathrm{~s}}+\mathrm{L}_{10} \mathrm{~s}\right)} \\
& +\frac{\frac{1}{\mathrm{C}_{\mathrm{s}} \mathrm{s}}+\mathrm{L}_{4} \mathrm{~s}}{\mathrm{C}_{4} \mathrm{~s}+\left(\frac{1}{\mathrm{C}_{4} \mathrm{~s}}+\frac{1}{\mathrm{C}_{5} \mathrm{~s}}+\mathrm{L}_{4} \mathrm{~s}\right)}+\frac{\frac{1}{\mathrm{C}_{7} \mathrm{~s}}+\mathrm{L}_{6} \mathrm{~s}}{\mathrm{C}_{6} \mathrm{~s}\left(\frac{1}{\mathrm{C}_{6} \mathrm{~s}}+\frac{1}{\mathrm{C}_{7} \mathrm{~s}}+\mathrm{L}_{6} \mathrm{~s}\right)}+\frac{\frac{1}{\mathrm{C}_{9} \mathrm{~s}}+\mathrm{L}_{8} \mathrm{~s}}{\mathrm{C}_{8} \mathrm{~s}\left(\frac{1}{\mathrm{C}_{8} \mathrm{~s}}+\frac{1}{\mathrm{C}_{9} \mathrm{~S}}+\mathrm{L}_{8} \mathrm{~s}\right)} \\
& \mathrm{R}_{1}+\mathrm{L}_{1} \mathrm{~s}+\frac{\frac{1}{\mathrm{C}_{3} \mathrm{~S}}+\mathrm{L}_{2} \mathrm{~s}}{\mathrm{C}_{2} \mathrm{~s}+\left(\frac{1}{\mathrm{C}_{2} \mathrm{~S}}+\frac{1}{\mathrm{C}_{3} \mathrm{~S}}+\mathrm{L}_{2} \mathrm{~s}\right)} \\
& \mathrm{C}_{1} \mathrm{~s}+\left(\mathrm{R}_{1}+\frac{1}{\mathrm{C}_{1} \mathrm{~s}}+\mathrm{L}_{1} \mathrm{~s}+\frac{\frac{1}{\mathrm{C}_{3} \mathrm{~s}}+\mathrm{L}_{2} \mathrm{~s}}{\mathrm{C}_{2} \mathrm{~s}+\left(\frac{1}{\mathrm{C}_{2} \mathrm{~s}}+\frac{1}{\mathrm{C}_{3} \mathrm{~s}}+\mathrm{L}_{2} \mathrm{~s}\right)}\right)
\end{aligned}
$$


To validate the input filter transfer function, an arbitrary voltage $V_{i n}=0.0499+j 0.0030$ was applied in the simulation, resulting in a voltage $V_{\text {out }}=0.0568+j 0.0041$ in charge. Therefore, $H_{\text {FilterIn }}=1.1+j 0.01$. Substituting the values of the capacitors, inductors and resistors in (1) and (2), it is obtained $H_{\text {FilterIn }}=1.0+j 0.02$ validating the expression.

The transfer function of the output filter is given by (3).

$$
H_{\text {Filterout }}=\frac{R_{2}}{R_{1}+R_{2}}
$$

To validate this expression, the output filter already modeled and with $R_{L}=10 \mathrm{k} \Omega$ was simulated for an input voltage $V_{\text {in }}=339 \mathrm{mV}$. The measured output voltage $V_{\text {out }}=338.9 \mathrm{mV}$. Thus $H_{\text {Filterout }}=$ 0.9999. Substituting these values of the input voltage and the values of the elements in (4) it is obtained $H_{\text {Filterout }}=0.9999$.

\section{B. Construction and Testing}

The series rectifier topology defined in Fig. 10 and in the Table $\mathrm{X}$ was manufactured with some variations. The inductor used as inductance passive element $12.38 \mathrm{nH}$ was replaced by an inductor of $10 n H$, due its commercial availability. A $56 p F$ capacitor was used since it is within the desirable range for this rectifier. A $50 \Omega$ SMA connector is used to connect the circuit to a signal generator which plays the role of an antenna harvesting electromagnetic energy from air. In addition to the known impedance, the SMA connector contains unknown inductance, capacitance and insert a signal delay so a model must be included in the simulation. Fig. 15 shows the manufactured rectifier circuit.

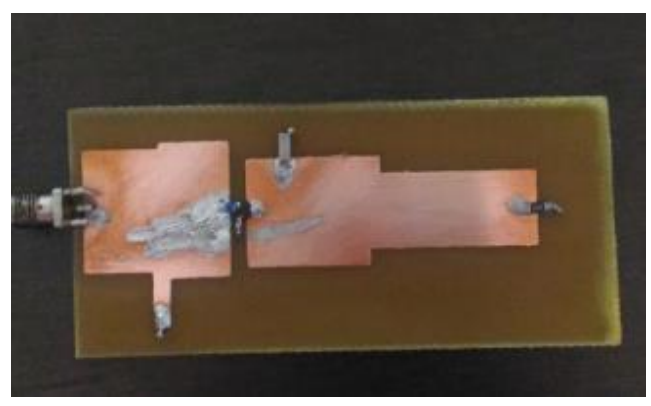

Fig. 15. Series Rectifier Circuit built.

To perform the measurements, the Agilent N5181A signal generator was set to generate a $-15 \mathrm{dBm}$ signal while the operating frequency range from $1 \mathrm{GHz}$ to $4 \mathrm{GHz}$. The Fluke 179 multimeter was coupled in parallel to the rectifier circuit load to measure the continuous voltage. The main results are in the graph in Fig. 16 which shows the load voltage as a function of the operating frequency for the laboratory measurement and the simulation for two cases: with and without the SMA connector. The output voltage, which was converted to voltage decibel scale (dBV) to improve graphic visualization, was chosen for this analysis because it is an optimization parameter and it is related to its efficiency through (4), where $V_{\text {in }}$ and $I_{\text {in }}$ are the input voltage and current respectively. The direct analysis of 
the voltage avoids propagation errors in the calculation of efficiency from real components and measurements.

$$
\eta=\frac{P_{\text {out }}}{P_{\text {in }}}=\frac{V_{\text {out }}^{2} / R_{L}}{\Re\left(V_{\text {in }} I_{\text {in }}^{*}\right) / 2}
$$

Comparing the circuit simulation without and with the connector, it can be seen that there is variation in output voltage and a frequency shift. These phenomena become even more evident when comparing the simulations with the measured output voltage and efficiency. Since the inductor used in circuit construction $(10 \mathrm{nH})$ is different from the one found in the optimization $(12.38 \mathrm{nH})$, there are consequences in the rectifier circuit response. As seen in Fig. 7(a), the variation in the inductance, even being small, interferes with the output voltage and circuit efficiency.

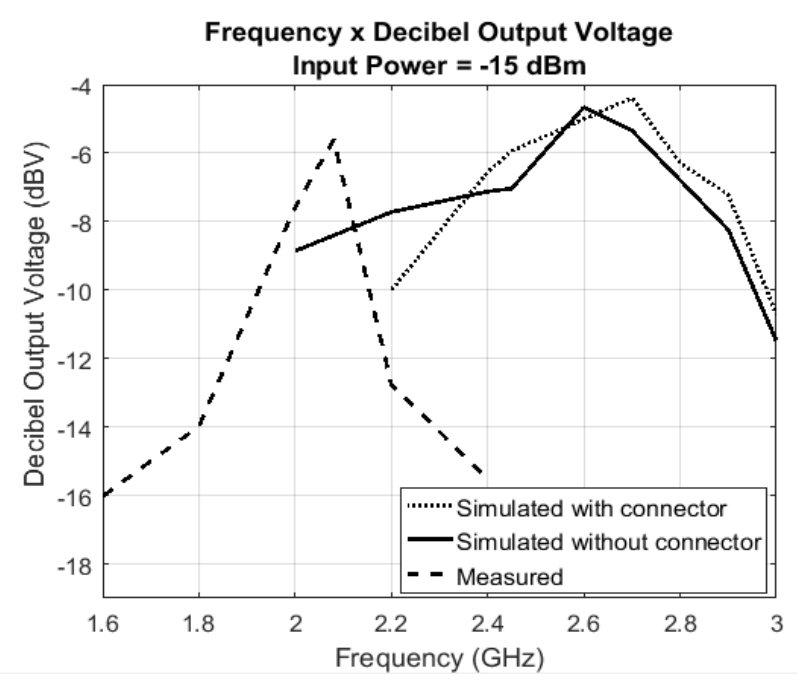

Fig. 16. Frequency x Decibel Output Voltage: Measurements and Simulations - $P_{\text {in }}=-15 \mathrm{dBm}$.

Fig. 17 shows the simulation of the circuit with $L=12.38 \mathrm{nH}$, as in the optimization and with $L=10 \mathrm{nH}$, as in the construction. It is possible to notice that the change of value of the inductor contributes to the frequency shift. Besides, it should be noted that the accuracy of the values of the components is generally between $5 \%$ and $10 \%$.

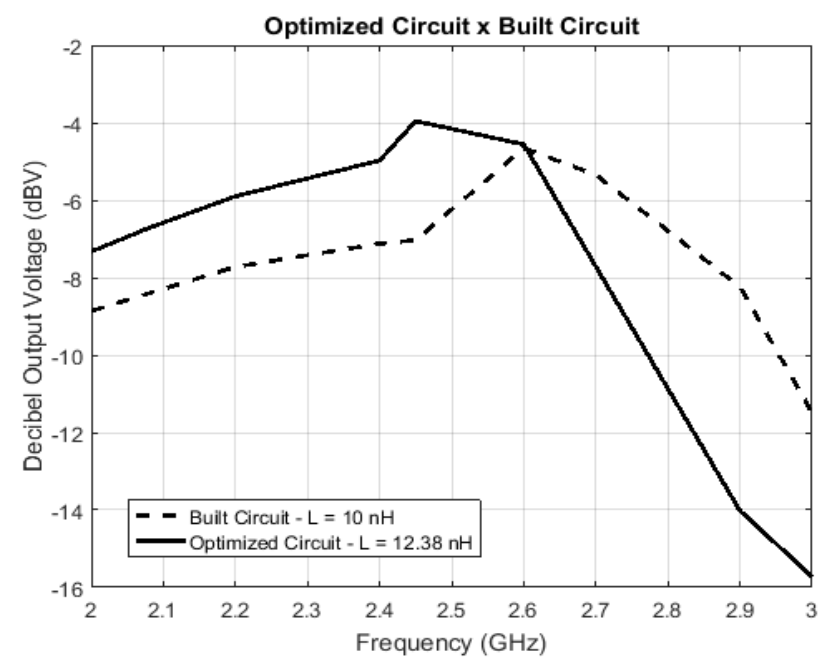

Fig. 17. Simulation of the Optimization Circuit $(L=12.38 n H)$ and Simulation of Built Circuit $(L=10 n H)$. 
Fig. 18(a) shows the simulation of the output voltage of the circuit for the worst case, that is, when the value of the inductor is equal to $10 \%$ of the expected. By observing the graph, it is possible to show again the frequency shift caused by the variation of the inductor, and also there is a variation of the output voltage. Fig. 18(b) shows the same simulation test for the resistor, which interferes only with the output voltage, not causing the frequency shift. Another issue not mentioned yet, but which can be observed through Fig. 16, is the influence of the SMA connector. When comparing the simulation with and without the SMA connector model, it can be seen a frequency shift.

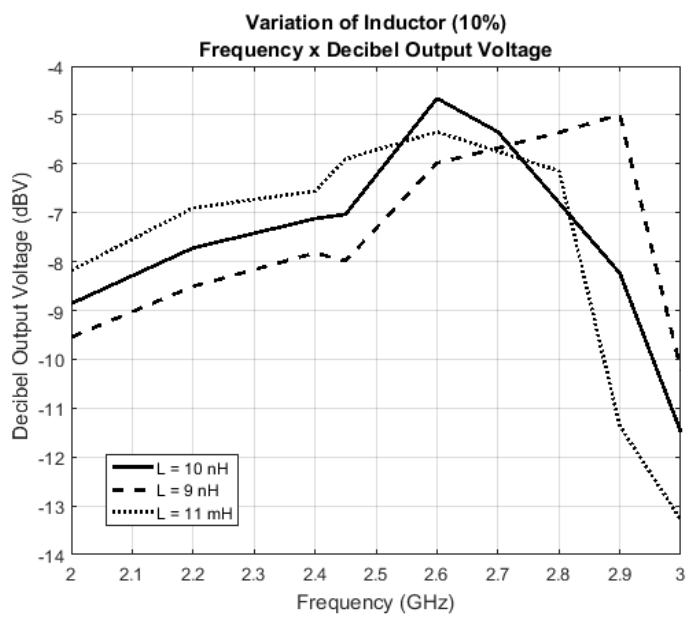

(a)

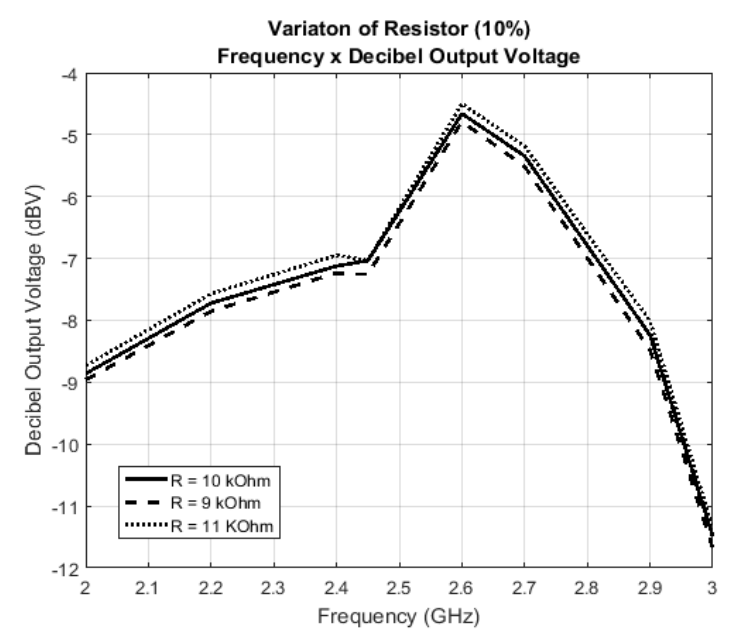

(b)

Hig. 18. Accuracy of Components: (a) Inductor and (b) Resistor.

Besides the passive components influence in the frequency shift, it must be remarked that there is an inconsistent behaviour of the FR4, especially at high frequencies [20]. Although the measurement of $S_{11}$ is centred the frequency in $2.45 \mathrm{GHz}$ and the adjustment of the inductor is made, the anisotropic characteristic of the material hinders the construction process of the simulated rectifier. Despite the facts mentioned, the behaviour of the simulated and constructed circuit is the same, validating the analysis performed for the same.

\section{CONCLUSION}

In this work the optimization of different topologies of rectifier circuits operating with ultra-lowpower for the purpose of harvesting and transmitting wireless energy was presented. After optimization, an interference analysis of factors such as input power, load, frequency and microstrip dimensions in the rectifier circuit response was performed and the best topology was chosen. The best result was found for the topology Series, which presented output voltage $V_{\text {out }}=402 \mathrm{mV}$, output power $P_{\text {out }}=16.13 \mu \mathrm{W}$ and efficiency $\eta=51.3 \%$. The innovative nature of this work is the analysis of the impact of each part of the rectifier circuit structure on its response and the mathematical modeling of the best observed circuit topology. Another differential in relation to the works found in the literature is the construction of the rectifier circuit in the FR4 material, which is specified for frequency up to $1 \mathrm{MHz}$ and presents high dielectric loss in centimetre band. Moreover, 
at high frequencies it presents anisotropies and not homogeneities what makes this dielectric very hard to model and simulate. Its use, however, is justified due to its low cost and easy access.

\section{ACKNOWLEDGMENT}

This study was financed in part by the Coordenação de Aperfeiçoamento Pessoal de Nível Superior - Brasil (CAPES) - Finance Code 001.

\section{REFERENCES}

[1] Y. W. Siang, "Wireless Power Transmission (WPT) Application at 2.4 GHz in Common Network," Ph.D thesis, Dept, Elec. and Comp. Eng, , RMIT Univ., Melbourne, AUS, 2010.

[2] J. Choi and C.Seo, "High Efficiency Wireless Energy Transmission Using Magnetic Resonance Based on Metamaterial With Relative Permeability equal to -1," Progress In Electromagnetics Research, vol. 106, pp. 3-47, 2010.

[3] D. C. Corrêa, U. C. Resende, F. S. Bicalho and T. S. Gonçalves, "Design, Optimization and Experimental Evaluation of a F-shaped Multiband Metamaterial Antenna," Journal of Microwaves, Optoelectronics and Electromagnetic Applications, vol. 17, no. 4., December 2018.

[4] A. Mabrouki and M. Latrach, "High Efficiency Low Power Rectifier Design using Zero Bias Schotty Diodes," IEEE Faible Tension Faible Consommation (FTFC), 2014.

[5] N. Akter, B. Hossain, H. Kabir, A. H. Bhuiyan, M. Yeasmin and S. Sultana, "Design and Performance Analysis of 10Stage Voltage Doublers RF Energy Harvesting Circuit for Wireless Sensor Network", Journal of Communications Engineering and Networks, vol. 2, pp. 84-91, Apr. 2014.

[6] X. Wu, J. Wang, M. Liu and H. Liu, "A High Efficiency Rectifier for Ambient RF Energy Harvesting at 940 MHz," IEEE International Conference on Microwave and Millimeter Wave Technology (ICMMT), 2016.

[7] U. Olgun, C. Chen, and J. Volakis, "Wireless power harvesting with planar rectennas for $2.45 \mathrm{GHz}$ RFIDs," in Proc. 2010 URSI Int. Symp. Electromagnetic Theory, 2010, pp. 329-331.

[8] U. Olgun, C. Chen, and J. Volakis, "Investigation of rectenna array configurations for enhanced RF power harvesting," IEEE Antennas Wireless Propag. Lett., vol. 10, pp. 262-265, Apr. 2011.

[9] A. Okba, A. Takacs and H. Aubert, "Compact Rectennas for Ultra-Low-Power Wireless Transmissions Applications," IEEE Transactions on Microwave Theory and Techniques, vol. 67, No.5. May 2019.

[10] C. R. Valenta and G. D. Durgin, “ Harvesting Wireless Power,” IEEE Microwave Magazine, pp. 108-120, Jun. 2014.

[11] Hewlett Packard - HP, “Surface Mount Microwave Schottky Detector Diodes,” Technical Data.

[12] D. H. Chuc and B. G. Duong, "Investigation of rectifier circuit configurations for microwave power transmission system operating at S Band," International Journal of Electrical and Computer Engineering, vol. 5, pp. 967-974, Oct. 2015.

[13] F. R. Enache, I. C. Vizitiu, C. I. Rîncu and F. G. Popescu, "Analysis of direct current nonlinearr electrical circuits by means of symboliccomputation and Genetic Algorithms," IEEE International Conference on Optimization on Electrical and Electronic Equipment, 2014.

[14] R. L. R. da Silva, S. T. M. Trindade, T. C. Fonseca and C. Vollaire, "Otimização Multiobjetivo Usando Algoritmo Genético de Retificadores Não Lineares com Baixíssima Potência de Entrada," XXXVII Iberian Latin American Congresso on Computational Methods in Engineering, Nov. 2016.

[15] J. H. Holland, “Adaptation in natural and artificial systems,” Ann Arbor University of Michigan Press, 1975.

[16] M. Heinola, K. P. Lätti, P. Silventoinen, J. P. Ström and M. Kettunen, “ A New Method to Measure Dielectric Constant and Dissipation Factor of Printed Circuit Board Laminate Material in Function of Tempetature and Frequency," 9th Int'l Symposium on Advanced Packaging Materials, 2004.

[17] K. P, Lätti, J. M. Heinola, M. Kettunen, J. P. Ström and P. Silventoinen, “A Review of Microstrip T-resonator Method in Determination of Dielectric Properties of Printed Circuit Board Materials," Instrumentations and Measurement Technology Conference, Ottawa, Canada. May 2005. 
Journal of Microwaves, Optoelectronics and Electromagnetic Applications, Vol. 19, No. 1, March 2020

DOI: http://dx.doi.org/10.1590/2179-10742020v19i11864

[18] C. A. Balanis, “Antennas Theory: Analysis Design,” John Wiley \& Sons, Inc. 3rd ed., 2005.

[19] V. Marian, C. Vollaire, J. Verdier and B. Allard, "Efficient Design of Rectifying Antennas for Low Power Detection", International Microwave Symposium 2011 (IMS2011), 5 - 10 Jun 2011, Baltimore (USA), 2011.

[20] H. Siahkamari, E. Heidarinezhad, E. Zarayeneh, S.A. Malakooti, S.M.H. Mousavi and P. Siahkamari, "Design of compact microstrip low-pass filter with analytical sharpness of transition band," International Journal of Microwave and Wireless Technologies, vol.8, no.7, pp. 1017-1022, 2016.

[21] J. Hong and M.J. Lancaster, "Microstrip Filters for RF/Microwave Applications", Copyrigth $\odot 2001$ por John Wiley \& Sons, Inc. 